\title{
Predicting the Actual Location of Faults in Underground Optical Networks using Linear Regression
}

\author{
Owusu Nyarko-Boateng ${ }^{1}$, Adebayo Adekoya ${ }^{2}$, and Benjamin Weyori ${ }^{2}$ \\ ${ }^{1}$ UENR \\ ${ }^{2}$ University of Energy and Natural Resources
}

May 7, 2020

\begin{abstract}
Optical cables are enormous transmission media which carries high-speed data across transatlantic, intercontinental, international boundaries and cities. The optical cable is essential in data communication. The cable has become an indispensable component in optical communications infrastructure; hence, conscious efforts are always adopted to prevent or minimize faults in the optical network infrastructure. Typically, tracing fault in the underground optical network has been difficult even though optical time-domain reflectometer (OTDR) has been used to measure the distance of faults in the underground fiber cable. The methodologies deployed in the reviewed literature indicate a vast gap between the fault distance measured by the OTDR and the actual distance of fault. This paper observed the difficulties involved in tracing the actual spot of fault in the underground optical networks. The difficulty of tracing these underground faults mostly result in an undue delay and loss of revenue. This research presents a machine learning (ML) approach to predict the actual location of a fiber cable fault in an underground optical transmission link. Linear regression technique was used to predict the actual location of a fault. Single-layer perceptron and sigmoid activation function were applied in the predictive model to obtain good accuracy value.
\end{abstract}

\section{Hosted file}

Manuscript_Edited - Ready.doc available at https://authorea.com/users/319287/articles/449022predicting-the-actual-location-of-faults-in-underground-optical-networks-using-linearregression 